\author{
Federal Reserve Bank of New York \\ Staff Reports
}

\title{
The Revolving Door and Worker Flows in Banking Regulation
}

\author{
David Lucca \\ Amit Seru \\ Francesco Trebbi \\ Staff Report No. 678 \\ June 2014
}

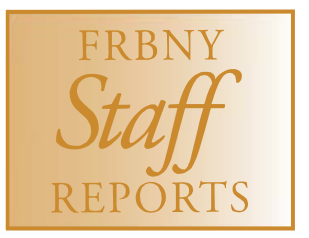

This paper presents preliminary findings and is being distributed to economists and other interested readers solely to stimulate discussion and elicit comments. The views expressed in this paper are those of the authors and do not necessarily reflect the position of the Federal Reserve Bank of New York or the Federal Reserve System. Any errors or omissions are the responsibility of the authors. 
The Revolving Door and Worker Flows in Banking Regulation

David Lucca, Amit Seru, and Francesco Trebbi

Federal Reserve Bank of New York Staff Reports, no. 678

June 2014

JEL classification: G21, G28

\begin{abstract}
Drawing on a large sample of publicly available curricula vitae, this paper traces the career transitions of federal and state U.S. banking regulators and provides basic facts on worker flows between the regulatory and private sectors resulting from the revolving door. We find strong countercyclical net worker flows into regulatory jobs, driven largely by higher gross outflows into the private sector during booms. These worker flows are also driven by state-specific banking conditions as measured by local banks' profitability, asset quality, and failure rates. The regulatory sector seems to experience a retention challenge over time, with shorter regulatory spells for workers, and especially those with higher education. Evidence from cross-state enforcement actions of regulators shows that gross inflows into regulation and gross outflows from regulation are both higher during periods of intense enforcement, though gross outflows are significantly smaller in magnitude. These results appear inconsistent with a "quid pro quo" explanation of the revolving door but consistent with a "regulatory schooling" hypothesis.
\end{abstract}

Key words: banking regulation, revolving door, inter-industry worker flows

Corresponding author: Lucca: Federal Reserve Bank of New York (e-mail:

david.lucca@ny.frb.org). Seru: University of Chicago. Trebbi: University of British Columbia. The authors would like to thank the editor Marvin Goodfriend as well as John Ferejohn, Joshua Gottlieb, Edward Kane, Deborah Lucas, Joseph Ma, Laura Pilossoph, Howard Rosenthal, Aysegul Sahin, Chester Spatt, Eugene White, Luigi Zingales, and Allen Zhang for useful discussion and comments. They are also grateful to participants at the November 2013 CarnegieRochester-NYU Conference on Public Policy and December 2013 Harvard Political Institutions and Economic Policy Conference, where this paper was presented. The authors are indebted to Jacob Conway, Moon Kang, Karen Shen, Lucy Shen, Navid Siami, Zachry Wang, and Allen Zhang for outstanding research assistance. Seru thanks the Fama Miller Center at the University of Chicago, which funded the project. The views expressed in this paper are those of the authors and do not necessarily reflect the position of the Federal Reserve Board of Governors, the Federal Reserve Bank of New York, or the Federal Reserve System. 


\section{Introduction}

According to a prominent narrative of the recent financial crisis, weakness in banking regulatory oversight and, in particular, regulatory capture was a key contributing factor in the buildup of risk ahead of the crisis. ${ }^{1}$ In conjecturing this link, a much talked about source of regulatory capture is the revolving door of regulatory personnel between the official and private sector that allegedly incentivizes regulatory personnel to soften their regulatory stance due to the prospect of future lucrative employment in the private sector. ${ }^{2}$ Future job opportunities may, on the contrary, incentivize regulators to toughen their oversight and favor complex regulations as these might enhance the subsequent value of regulators, should they transition to the private sector. Other commentators have downplayed distortions of the revolving door in either direction and presented a more benign viewpoint of revolving doors as a means for regulatory agencies to attract higher ability and skilled workers. Despite the continuing debate on this issue and numerous policy prescriptions, little systematic evidence exists on the incidence and drivers of the revolving door -- i.e., worker transitions between the banking regulatory and private sectors.

In this paper we attempt to fill this gap with two goals. First, we provide basic facts on worker flows between the banking regulatory and private sectors by examining worker transitions resulting from hirings and separations. Second, we characterize these flows in terms of their business cycle variation, job creation and destruction in the two sectors (Davis, Faberman and Haltiwanger, 2006) and worker characteristics such as human capital and seniority. As well, we study worker flows as a

\footnotetext{
${ }^{1}$ Banking regulation and supervision are complementary, but distinct activities. Regulation involves issuing rules that mandate or restrict certain banking activities for safety and soundness or other reasons, such as consumer protection. Supervision instead involves monitoring, inspecting and examining banks as well as enforcing corrective actions if banks are deemed deficient. In this paper we do not explicitly distinguish between these two activities, and collectively refer to agencies involved in either regulation or supervision as regulators.

${ }^{2}$ For instance, Cohen (1986) states that the revolving door hypothesis implies that the prospect of a future job in the regulated industry promotes support for the regulated industry. Similar discussions on revolving door hypothesis have a long pedigree in political science (e.g., see Gormley (1979)), in theory of regulation (e.g. Salant (1995)) and in law and economics such as recent work on financial regulators (deHaan et al. (2012)).
} 
function of intensity of regulatory activity to assess if worker flows in the aggregate can shed light on different views of revolving door.

The main obstacle in studying worker flows between the regulatory and private sector is a lack of available data. A large literature has studied direct job-to-job flows (Blanchard and Diamond 1990; Fallick and Fleischman 2004), and more closely to this paper, inter-industry job transitions (for example, Artuc, Chaudhuri and McLaren 2010) with longitudinal and cross-sectional data surveys. However, because banking regulators account for only a tiny fraction of all US workers, none of these sample surveys is detailed enough to construct worker flow statistics for the regulatory sector. ${ }^{3}$ We circumvent this challenge by constructing a unique dataset of career paths of more than 35,000 former and current regulators across all regulators of commercial banks and thrifts -- the Federal Reserve Banks (Fed), the Federal Depository Insurance Corporation (FDIC), the Office of Comptroller and Currency (OCC), the Office of Thrift Supervision (OTS), and state banking regulators -- that have posted their curricula vitae (CVs) on a major professional networking website. Our sample spans the past twenty-five years and provides a unique view into the process of selection and transition of personnel from these regulatory agencies to the private sector. After detailing our approach to construct worker transitions, which is new in the literature, and contrasting its shortcomings and strengths to labor data surveys, we study worker flows both in the aggregate and using panel regressions at the worker level.

Our data reveal clear evidence of countercyclical net worker inflows into the regulatory sector. Net worker flows from the private sector to the regulatory sector fall significantly and are often negative in good times, which may be the result of higher gross inflows to the regulatory sector in bad times or higher gross outflows in good times. Looking at the data, we find that higher gross outflows to

\footnotetext{
${ }^{3}$ As we discuss in more detail in the paper, key sources include such as the Current Population Survey (CPS), the Panel Study of Income Dynamics (PSID) and the Survey of Income and Program Participation (SIPP).
} 
the private sector in good times are a key driver of the countercyclical regulator net worker flows. We also find evidence of higher gross inflows in regulation in bad times as well as in the past few years, likely due to strong regulatory demand linked to enhanced banking supervision following the financial turmoil.

We investigate in more detail the potential sources of inflows and outflows from regulatory jobs by assessing the relationship of worker flows with relative demand-side proxies for job-creation or destruction in the banking and regulatory sector. Job creation in the regulatory as compared to the banking sector is likely to be positively related to measures of banking stress and inversely related to bank profitability, with opposite patterns expected for job destruction. Indeed, after controlling for aggregate economic conditions, net regulatory inflows tend to be higher in periods and states where local banks have lower ROAs, higher non-performing loan ratios, as measured from Call Reports, and higher occurrences of bank failures. Overall, we find regulatory job mobility to be much lower than in the private sector. On average, gross-worker flows between the regulatory and private sector is less than half the job-to-job transitions in the private sector as measured from a benchmark sample we employ and data from the Current Population Survey (CPS). ${ }^{4}$

Next, using information obtained from the workers' CVs and the fact that our dataset is longitudinal, we examine the selection of individuals into and out of the regulatory sector by assessing which individuals enter and exit banking regulation over the business cycle, as a function of their human capital (i.e., their education levels) and skills/connections (i.e., their seniority in the regulatory organization). We find that the best talent, as proxied by higher human capital, has shorter regulatory spells because of higher outflows to the private sector. We also find that more senior staff, not surprisingly, spend more time in regulation. While we find no significant differences in the business

\footnotetext{
${ }^{4}$ Because regulator-to-regulator flows are tiny in our sample, regulator-to-private flows or private-to-regulator flows are all job-to-job transitions experienced by current or next-period regulatory employees.
} 
cycle sensitivity across different human capital levels, overall, the regulatory sector appears to face a retention challenge when it comes to individuals with higher human capital based on their shorter regulatory spells. Consistent with this finding, we also find that regulatory spells have been declining in the past twenty-five years. For example, while about $88 \%$ of workers that started working in regulation in 1988 spent three or more years in regulation, only 64\% of workers that started working did so two decades later.

We briefly turn next to an analysis that explores aggregate regulator mobility as a function of regulatory actions. According to one prominent view (the “quid-pro-quo” view), future employment opportunities in the private sector affects, as a quid pro quo, the strictness of actions of a regulator while the individual is employed in the regulatory sector. This hypothesis implies that we should observe lower gross outflows from regulation to private banking during periods of high enforcement activity. Understanding whether this hypothesis may be at play is important since destabilizing banking crises have often been ascribed to weak regulatory oversight. Based on an alternative view of the revolving door (the "regulatory schooling" view) regulators may instead have an incentive to favor complex rules because "schooling" in these regulations enhance regulators future earnings, should they transition to the private sector. ${ }^{5}$ Such a hypothesis would imply high gross inflows into regulation at times of higher regulatory intensity as workers are schooled in the new rules as well as high gross outflows from regulation into the private sector as regulators earn returns from schooling in the new rules. According to the regulatory schooling view, inefficiencies may derive not from laxity, but on the contrary from more complex regulations.

In order to shed light on these hypotheses, we relate worker flows to intensity of supervisory activity in the data. We measure each regulator's strictness using their formal enforcement activity in a given state and year and focus on the most severe of these actions: terminations or suspensions of deposit

\footnotetext{
${ }^{5}$ We thank the editor for suggesting this alternative view.
} 
insurance as well as cease-and-desist orders and prompt corrective action directives, for which failure to comply are all grounds for receivership. While enforcement activity is not a measure of regulatory complexity per se, as discussed in Agarwal et al. (2014) the final impact of rules on regulated entities is the result of both regulations and the manner in which these are enforced through supervisory activity. Empirically, we find a positive association between the intensity of strict actions over time and across states and the net inflows into the regulatory sector. Looking more closely at gross flows, we find that this relationship is driven by more inflows into regulatory jobs in periods of high enforcement/more intense regulatory activity. Gross outflows from the regulatory sector are, in fact, higher around periods of higher enforcement activity. We find similar patterns when we focus on cross-state variation only by including time fixed effects. This implies that the association between regulator activity and worker flows is identified even when we use variation across states and regulators and is not just capturing aggregate economic conditions. Based on the discussion above, the patterns we uncover are opposite of what would be implied by a quid pro quo story but are instead consistent with the regulatory schooling story. These patterns are consistent with Agarwal et al. (2014) who find higher turnover of state regulators into private sector if these regulators give harsher supervisory ratings to banks under their supervision.

This evidence is admittedly naïve to some extent and not a ubiquitous test of the quid-pro-quo or regulatory schooling hypothesis. For instance, it cannot rule out the presence of distortions in banking regulations at a more micro level or whether regulations are more complex as a result of the schooling hypothesis. Uncovering whether revolving doors distorts regulatory effectiveness at a smaller scale or leads to regulators favoring excessive regulatory complexity remain open questions requiring more research. A recent paper by Shive and Forster (2014) takes a promising step in this direction. 
This paper is most directly related to work studying revolving doors in banking regulation. Most of this work (for example, Johnson and Kwak 2010) is normative in nature but relies on case studies or other anecdotal evidence. Our analysis, which relies on a new data collection, is instead mainly positive, and we therefore see it as complementary the existing work. ${ }^{6}$ More generally this paper is also connected to a vast literature in both political economy and banking on the role of regulation and its potential distortions (for examples, specific to banking: Kroszner and Strahan 1999, Berger and Hannan 1998, Barth et al. 2004; Agarwal et al. 2014, and more in general: Besley and Coate 2003). Finally, our work is related to the labor literature on job-to-job transitions and intersectoral job transitions, mentioned above, and to the modern approach to labor flows (Davis, Faberman and Haltiwanger, 2006) from which we borrow methods and definitions, while proposing a new approach to computing worker flows.

\section{Data, Sample Construction and Descriptive Statistics}

Studying regulatory worker flows resulting from the revolving door requires information on job-tojob transitions between the banking regulation sector and the private sector. Available empirical measures of aggregate job-to-job and cross-industry transitions in the labor literature are typically constructed using either the Current Population Survey (CPS), the Survey of Income and Program Participation (SIPP), or the Panel Study of Income Dynamics (PSID). Fallick and Fleishman (2004) construct job-to-job transitions from matched monthly data from the CPS, while Nagypal (2008) uses SIPP data, which contains occupational information at weekly frequency and thus limits issues of temporal aggregation bias. ${ }^{7}$ Direct cross-industry transitions occur less frequently than overall job-to-job transitions, and so most studies (for example, Artuç, Chaudhuri, and McLaren, 2010) rely

\footnotetext{
${ }^{6}$ Other studies on the revolving door based on empirical data, albeit outside banking regulation, include Cohen (1986) who shows that Federal Communications Commissioners who end up working in the industry after their tenure shift their voting pattern toward more support for the industry in their final year of service. There is a larger body of work that explores the value of lobbying (see, Blanes I Vidal et al. (2012) and Bertrand et al. (2013)).

${ }^{7}$ For example, the CPS may overstate transitions relative to SIPP because job-to-unemployment-to-job transitions may be misclassified as direct job-to-job transitions. That said, SIPP as been shown to suffer from "seam biases", that is statistics computed across the "seam" between two successive survey administrations differ from those obtained within a single interview (see for example Moore, 2007).
} 
on the CPS because with about 60000 households, the survey has the largest sample size among publicly available sources of worker flows. ${ }^{8}$

The CPS contains information on the Census Industrial and Census Occupational Classification for each individual in the survey that is occupied. The Industrial Classifications only contain eight categories for the official sector (public administration), so the only hope to construct flows for workers in banking regulation would be to proxy their identity by conditioning on industry and their occupation. Doing so, however, stretches the limits of the CPS survey sample. For example, from 2003 we could only match a total of 15 instances per annum of financial examiners working in public administration matching monthly data as in Shimer (2012). Accounting for the fact that each individual can be observed only in six pairs of consecutive months in the CPS, this handful of observations corresponds to only about a pair of individuals each year. Given the limited usefulness of available data sources, we turned to an alternative method to compute cross-industry worker transitions that directly samples individuals employed in banking regulation.

\subsection{Data and Construction of Worker Flows}

The empirical analysis in the paper relies on a sample that is constructed using career transitions from CVs in the database of a leading social networking website for professionals. In this section we provide an overview of the method used to construct a sample of individuals who have worked in a banking regulatory institution at any point in their career starting in the 1980s.

Our main sample includes current and former employees of all U.S. banking regulatory institutions: the Federal Deposit Insurance Corporation (FDIC), the Office of the Comptroller of the Currency (OCC), the former Office of Thrift Supervision (OTS), the Federal Reserve's Board of Governors and Reserve Banks, and state banking departments. Figure 1 illustrates what constitutes the scope of

\footnotetext{
${ }^{8}$ The CPS has limited longitudinal information as each household remains in the panel for eight months, with a gap of eight months after the first four months. Thus studies (for example, Loungani and Rogerson 1989) that require longitudinal data, such as permanent cross-industry transitions, have relied on the PSID.
} 
this paper. To form the sample, we search all profiles in the database for workers with a regulatory spell in their current or past employment information.

Based on these selected profiles, we collect each worker's information focusing in particular on the career path of each individual, the position he or she has in a given job, and for each position, his or her company name, start date, and end date. We also determine the chronological order of the positions using their arrangement on the profile page, and assign to each worker a unique identifier. Based on our search criterion, we obtained 21,396 profiles of individuals who have worked at some point for the Federal Reserve, 6,958 profiles of individuals who have worked at some point for the FDIC, 3,418 profiles of individuals who have worked for the OCC, 646 profiles of individuals who have worked for OTS, and 3,186 profiles for individuals who have worked for one of the state regulators, for a total of 35,604 profiles. We perform additional data cleaning by using the unique ID mentioned above to remove duplicate individuals who may have worked in more than one regulatory agency and that were therefore downloaded more than once. In the end, we are left with 34,064 unique profiles of individuals who have worked at any point in time during their careers in the regulatory agencies we have mentioned above. We also build a benchmark sample ("neverregulator" sample) of career movements outside the regulatory sector using CVs of a sample of individuals who are never employed in the regulatory sector but have worked at least once in the firms included in the treatment sample. ${ }^{9}$

Once the CVs are acquired, we reshape the data in the CV, which is reported at each job level to a panel that lists an individual's name and work information in each period. While we have

\footnotetext{
${ }^{9}$ In particular, we start with the list of firms that each individual in the treatment sample has ever worked in. This gives us a list of 113,548 instances. We sample from this list, which includes repeat firms, since we are interested in the empirical distribution of firms that individuals in the regulators sample are employed by. We randomly pick 34,064 instances from this list and download a profile from each selected firm. This procedure ensures that we match the empirical frequency of firms that individuals in the regulators sample have worked for at some point in their career. For example, it is reasonable to expect more individuals in the regulators sample would work for large banks. Our procedure ensures that we sample more individuals in the never-regulators sample from such banks.
} 
information at the monthly level for a number of CVs, we define a period to be a year in our analysis both for computational reasons and because monthly information is often missing.

A key issue that we face when reorganizing the information from the CVs into the panel are multiple overlapping job spells; that is, some individuals may list several occupations over the same period. While we track all occupations for all the individuals in our sample, we need to make some assumptions when performing the analysis on career transitions. In particular, we limit our analysis to individuals that list a maximum of three simultaneous occupations in a year. These individuals account for more than $90 \%$ of our original sample. In order to deal with missing spells or holes in CVs we classify an individual as unemployed if there is a one- or two-year long time gap between job (or education) spells, and we instead classify a spell as having missing information if the time gap between two spells is longer than two years. Based on these rules, at any given point of time we classify individuals into one of four activity categories: private sector, regulatory sector, student, and unemployed. We turn next to a description of our sample. ${ }^{10}$

Figure 2 plots the total number of active individuals in our sample as well as the number split by each of the regulatory agencies in our sample over time. The black line in the panel on the left (Figure 2A) shows that there are about 30,000 active individuals at the end of our sample in 2013, which is when we collected the CV information. Also evident from the chart is a thinning in the number of individuals as we go further back in time. The reason is twofold: first, younger individuals that have a shorter work history are more likely to post online, and second, careerinactive individuals are less likely to post (that is, we cannot collect CVs for inactive workers). These cohort effects make our panel unbalanced.

\footnotetext{
${ }^{10}$ As noted in Section 2.1, there is also a small fifth category, "unusable" or inactive, for periods when individuals have missing information in their job history for a period of longer than two years.
} 
As shown by the thin grey line in Figure 2A, similar cohort effects are also present in the benchmark never-regulators sample. The similarity of the pattern between the two groups suggests that the cohort effect is not specific to the sample of regulators, but rather the result of constructing a longitudinal dataset from CV information collected at one point in time. As will become apparent in the empirical section, we will explicitly control for these effects with individual-specific or cohort fixed effects in order to ensure that our empirical results are not affected by the panel structure.

In Figure 2B, we plot the number of individuals by regulatory agency, as measured by having at least one employment spell with a given regulator. In particular, we trace the number of career active individuals that have worked for a given regulator at any point in time in their career. We only find a very small fraction (less than half a percent) of cases where individuals work for multiple regulatory agencies, or in other words for essentially all individuals in our sample, workers have a single regulatory-institution stint. The figure shows that, similar to Figure 2A, there is thinning as we go back in time in the number of individuals who report having worked for any of the regulatory agencies, except the OTS. In addition, it is clear that the regulators sample consists primarily of individuals who have worked for the Fed (both Reserve Banks and the Board of Governors) and the FDIC (almost two-thirds of the total). ${ }^{11}$

\subsection{Descriptive Statistics and Variable Definitions}

We present in Table 1 summary statistics for our main variables of interest, split by whether these measures are used in a panel (1A) or cross-sectional analysis (1B). Our empirical analysis mainly relies on transitions between private and regulatory sectors. As discussed in the previous section we track each individual's status (employed in banking regulation or in the private sector, student or

\footnotetext{
${ }^{11}$ Comparing the number of workers in our sample to headcount of regulators, which we obtain from each agency's Internet website, we find that while the total headcount in each agency fluctuates from year to year (especially around recession, as we will see), overall it remained fairly stable, or declined, over time. For instance, the total number of full-time employees (irrespective of occupation) at the Fed has remained roughly 22,000 in the sample period, with a bit of decline in recent years. Full-time employees at OTS declined on net through 2010, the last year of that agency during our sample period. Finally, the FDIC has had roughly 8,000 full-time employees during the last twenty years, but significantly more in the years before then.
} 
unemployed) at a yearly frequency. To establish the timing of a transition from one job to another we track worker information in the year prior to and following a switch to resolve timing ambiguity in the case of multiple listings. For example, if an individual lists both private and regulatory sector employment in year t, we use data in the following and preceding year to determine the direction and timing of the transition. ${ }^{12}$ Based on these guidelines, we define the dummy variable "Into (Out) Reg Status", which indicates if a transition into (out of) the regulatory sector occurs in a given year for an individual in our sample, and "ARegulator Status" which is equal to the difference between the inflow and outflow dummies. Because our data is measured at yearly frequency our measures of direct inter-industry transitions are subject to aggregation biases similar to other measures of annual job-to-job transitions used in the labor literature. For example, a transition from the private sector to a spell of unemployment that lasts less than 12 months and then into regulation will be recorded as a direct transition in our data. In other words, our measures of direct inter-industry transitions may include some indirect transitions that include a short unemployment spell.

We also use transition dummies to exploit longitudinal information in our sample and track worker information such as the first year in which he or she enters a regulatory spell, as well as the length of time that is spend in the regulatory sector. Based on the information that we obtain from the CV we also construct measures of an individual's seniority (seniority) within the regulatory organization and maximum level of education attained (human capital).

We finally match employment information to other data sources such as aggregate measures of economic activity: NBER-dated indicators and year-on-year real-GDP percent growth rates. We also construct measures of enforcement activity at the state and year level (reported in 100s in Table 1), based on the number of harsh enforcement actions for each federal regulatory agency obtained

\footnotetext{
${ }^{12}$ For example a private job in year $\mathrm{t}-1$ and $\mathrm{t}$ and a regulatory job in year $\mathrm{t}$ and $\mathrm{t}+1$, implies that a transition into regulation occurred in period $t$.
} 
from each agency’s website. We describe these measures in more detail below. Finally we use Call Reports and data from the Federal Reserve's National Information Database, to track time variation in return on assets $(R O A)$ for commercial banks and thrifts in each state, as well as the fraction of non-performing loans relative to their loan book (either 90+ delinquent or in non-accrual status) and the total number of bank failures in each state (also reported in 100s in the Table). We turn to our empirical results next.

\section{New Facts on Regulators’ Transitions}

This section presents a first set of stylized facts concerning aggregate worker flows into and out of the banking regulatory sector and then studies how these flows relate to observable characteristics such as worker education and job seniority.

\subsection{Economic Cycles in the Revolving Door}

\section{Net Worker Flows}

In this section we characterize how worker flows into and out of the regulatory sector vary with economic conditions. We first analyze the aggregate data graphically and then use panel-level regressions at the year and worker levels. We run this analysis starting in 1988 and ending in 2013 for the sample of regulators, which, as discussed above, is defined by all workers that have been employed by a banking regulator at some point in their career. The choice of our starting date balances the more limited availability of information in the early 1980s and our interest in studying worker flows around the 1990-91 recession.

Figure 3 plots net worker flows (measured on the left scale) against macroeconomic conditions as measured by real GDP annual growth rates (dashed lines) and NBER recessions (shaded vertical areas). Net private-to-regulator worker flows (thick black line) are defined as the share in each year of all active workers in our sample that transition from the private sector to the regulatory sector, less 
the share of transitions out of the regulatory and into the private sector. We also show total netregulator flows (thin black line), which include transitions in and out of the regulatory sector to the private sector, as well as to student status and to unemployment, as a share of all individuals in our sample.

Focusing on the net private-to-regulator worker flows, it is apparent that these flows are countercyclical. Net worker flows into the regulatory sector are lower (mid-2000s) and turn negative (1990s) outside economic recessions; that is, workers exit regulation, on net, during normal economic times and tend to enter regulation in bad economic times. Indeed, we observe an increase in net worker flows from the private sector into regulatory sector during all three recessions in the sample. In addition, strong net inflows are evident a couple of years following the 2007-09 recession, but then decline thereafter. The likely driver of these inflows is the implementation of, and enhanced supervisory monitoring under, the Dodd-Frank Act, which boosted the demand for workers in the regulatory sector. Given the exceptional circumstances around these years and the recent financial crisis, we will explore the robustness of our regression results to the exclusion of the post-2007 sample. Overall, throughout the sample, private-to-regulator net worker flows have a correlation of - 0.6 with the GDP-growth measure, and similar correlations are also present with other indicators of economic condition such as the unemployment rate (.75; not shown). We return to these patterns in our panel regressions below.

Aside from flows from the private sector, total net flows into regulation may also be driven by flows from schooling and unemployment. Figure 3 shows what we refer to as "total net regulator flows," which includes these other flows. The time-series variation in the total net flow series is extremely similar to the net flows from private sector to regulatory sector, highlighting that the time series variation in net regulator worker flows is dominated by direct private sector flows. Given our interest 
in "revolving doors" and their key importance in total net flows into regulation, we focus on this category in our empirical analysis below.

We turn next to the panel regression analysis, which allows us to more formally establish the cyclical (and other) patterns of regulatory worker flows after controlling for potential sampling issues such as the unbalanced nature of our panel due to cohort effects as discussed in Section 2. One of the key dependent variables in our regressions is $\Delta$ Regulator Status $_{i t}$, which measures for each individual $i$ transitions in and out of employment in the regulatory sector between year $t$ and $t$ 1. In particular, the dependent variable takes a value of 1 for an individual who is employed in regulation today but was not in the regulatory sector last year, 0 if an individual stays in the same activity today and tomorrow (i.e., if she or he is either in regulation in both periods or not in regulation in both periods), and -1 if an individual who was employed in the regulatory sector last year is in the private sector this year. To establish the cyclical patterns, we use current and lagged values of an NBER Recession Indicator, which measures the number of months each year that have been classified by the NBER as being part of a recession.

Let us indicate with $y_{i t}$ our dependent variable of interest for individual $i$ in year $t$. The specification we employ is:

$$
y_{i t}=\alpha X_{t}+\beta Z_{i t}+\varepsilon_{i t}
$$

where $X_{t}$ measures the key variable of interest such as proxies for economic conditions, and the vector $Z_{i t}$ is a vector of additional regressors as discussed next. To understand this specification, consider the case in which no additional explanatory variable $Z_{i t}$ is included and the dependent variable is $\Delta$ Regulator Status $_{i t}$. Because net worker flows into regulation are in each year equal to the mean of the dependent variable, $\alpha$ in (1) recovers the time series relation between net worker flows and real GDP growth shown in Figure 3 if $X_{t}$ is set equal to real GDP growth. 
Beyond recovering the coefficient in the aggregate coefficients model (1) allows to control for potential sampling issues through the additional variables in $Z_{i t}$. The main concern is that the cyclical patterns that we may recover in the aggregate may be distorted because of the unbalanced nature of our panel (Figure 2). As discussed in Section 2, the likely key drivers of the panel structure are cohort effects. We control for these effects through either individual fixed effects or when we study additional cross-sectional determinants (such as education or seniority) through cohort-group effects. These effects are defined as all individuals whose first career entry year on their CV is within a five-year band, beginning with 1964 (i.e., cohorts are defined as dummies for individuals whose first career entry on the CV is between 1964 and 1968, 1969 and 1973, etc.). Finally, to guard against the alternative that cohort effects may be driving the thinning in the number of individuals going back in time, and to control for potential trends, we also include a quadratic polynomial in time. This specification is sufficiently flexible to capture the sample size evolution over time in Figure 2. We always report standard errors clustered at the locality level, which controls for potential serial correlation in the error terms at a regional level.

Table 2A reports the regression estimates. Column 1 presents results for pooled analysis on the entire sample starting in 1988. Matching the aggregate patterns shown in Figure 2, the coefficient on concurrent Recession is both positive and highly statistically significant. To account for possible delayed effects of economic conditions on net worker flows we also include a lagged recession indicator, and we indeed find similar effects in the year following a recession (column 2). We next include additional controls in the regression to guard against sampling issues as discussed earlier. As shown in the remaining columns, the results change little if we include cohort fixed effects (column 3), include individual fixed effects (column 4), exclude the recent financial crisis (i.e., use the period 1988-2006) (column 5) and finally proxy for economic conditions using real GDP growth (column 
6). The magnitudes of the relationship between net regulatory worker flows and economic conditions are economically large. For instance, when using within-individual variation in column 4, the propensity to move into banking regulation increases by around 2 percentage points around a recession year $([0.013+0.027] / 2)$, which is about as large as the average within-worker net transition rate in the sample (2.1\%, reported at the bottom of the table) and about $13 \%$ of the within-worker standard deviation (14\%). Similarly, estimates from column 6 suggest that a one-standard-deviation decline in real GDP growth rate would increase the transition rate out of the regulatory sector by roughly $40 \%$ relative to the average within-individual transition rate.

\section{Inflows and Outflows}

The countercyclical relationship between economic conditions and net flows into banking regulation can occur because of two channels: either gross inflows into regulation increase, or gross outflows from regulation decline. In this section we study each gross flow separately to establish their relative importance and then link these measures to proxies of job creation and destruction in the regulatory and private sectors.

Figure 4 shows gross worker flows in our main sample (of individuals that have been in the regulatory sector at least once in the sample). Several patterns emerge. First, through the mid-2000s, worker regulator outflows to the private sector outside the recessions average around 3.5\% in 1990s (peaking at 5\%) and around 3\% in 2000s. During this period, the rate of worker flows from private sector to regulatory sector is relatively flat at around 3\%. As a result, the countercyclical net flows into regulation are driven to some extent by more individuals exiting the regulatory sector in good times. We also observe that worker regulator inflows increase to some extent in economic

downturns, consistent with either higher job creation in regulation or higher attractiveness of regulatory jobs versus private ones in bad times. The regulatory demand likely dominates regulatory inflows in the post-2007 sample, due to increased demand for regulation following the recent 
financial crisis, and over this time we also observe an increase in outflows, although to a lesser extent.

More formally, in Table 2B, we study the relation between economic conditions and gross inflows and outflows separately in a panel regression analysis. We use gross inflows from private sector into the regulatory sector as the dependent variable in the odd columns (1, 3, and 5). The variable Into

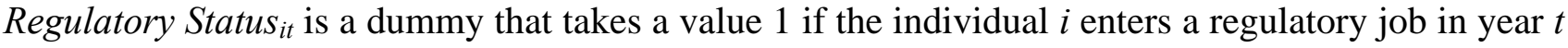
from a private sector position in $t-1$ and is 0 otherwise. Similarly, in the even columns (2, 4, and 6) we study gross outflows from regulatory sector to private sector with a dummy variable, Out of Regulatory Status $_{i t}$, which takes a value 1 if the individual $i$ exits a regulatory job to private sector in year $t$ and is 0 otherwise. As in Table 2A, we control for cohort effects and sampling issues using individual fixed effects and a quadratic trend.

Our results confirm the cyclical patterns shown in Figure 4. Throughout the sample the cyclicality of net flows is the result of higher regulatory inflows and lower outflows around recessions (columns 1 and 2). When excluding the post-2007 sample (columns 3 and 4) or when conditioning on GDP growth, however, net flows are dominated by the procyclicality of gross outflows to the private sector. For instance, column 4 shows that, on average, there is a decrease in gross outflows from the regulatory sector of around $1.35 \%$ around NBER-dated recessions ([.011+.016]/2). In contrast, column 3 shows that the increase in gross inflows into the regulatory sector of around $0.15 \%$ around the recessions ([.008-.005]/2). Comparing columns 1 and 2 with 3 and 4, we confirm that, as noted earlier, the importance of gross inflows in the full sample is due to the post-financial-crisis period.

Worker flows are determined both by supply-side conditions, such as workers entering or exiting the labor force, as well as demand-side factors that drive employers' job creation and destruction 
decisions. Next, we investigate further the potential sources of inflows and outflows by assessing the relationship of worker flows with proxies for job-creation or destruction in the banking and regulatory sector over time. In particular, in Table 2C we use specifications similar to those in Table 2A-B, but also include the profitability of the banking sector in each year and state, as measured by each year's $R O A$ for banks in a given state, to proxy for job creation in the banking sector. We also include proxies of banking stress, \% Non-performing loans in the portfolio of banks in a given stateyear, as well as the yearly local Total Bank Failures to proxy for job creation in the regulatory sector as well as destruction in the banking sector. As can be observed, we find the earlier relation that net worker flows into the regulatory sector are countercyclical -- and this variation is driven primarily by worker outflows. In addition, columns 1 and 2 show that net flows into the regulatory sector are related to job creation/destruction proxies in the two sectors. Net flows into regulation fall when the banking sector does well and rise at times of banking stress, which is when the regulatory sector faces an increased worker demand. Looking at gross flows, we see that both worker inflows and outflows are driven by the three measures of banking sector conditions (columns 3 to 6).

In sum, countercyclical worker flows into the regulatory sector are primarily due to higher gross regulatory outflows in good times up to the financial crisis. These flows are driven to some extent by the health of the banking sector as measured by its profitability and asset quality. Gross inflows, which tended to increase marginally during recessions, have become more important in the aftermath of the recent financial crisis, likely due in part to the higher regulatory demand.

\section{Regulatory Worker Flows and Job-to-Job Flows in the Private Sector}

As a benchmark to assess the magnitude of the regulatory worker flows we briefly turn to the neverregulators sample. Using this data, we construct private sector worker job-to-job flows as the fraction of active individuals who change jobs within the private sector between years $t$ and $t-1$. On 
average we find that job transitions average to about $20 \%$ in our sample period. ${ }^{13}$ The average frequency in the data is very similar to the job-to-job transition rate from CPS data. Using monthly CPS data matched as in Shimer (2012) for all types of workers we find annualized job-job-transition annualized probabilities of about 26\% through 2012 and of about 22\% in the finance and insurance sectors (based on the Census Industrial Classification). ${ }^{14}$ These numbers are very similar to the jobfinding rate in the never-regulator sample.

Because as noted above, regulator-to-regulator flows are very small in our sample, regulator-toprivate and private-to-regulator flows represent job-to-job transitions for (current or next period) regulatory employees. From Figure 3, total private-to-regulator and regulator-to-private flows add up to about 9\% in the regulator sample (excluding students, inactive individuals and unemployed), which is less than half the private sector job-to-job flows in the never-regulators sample. ${ }^{15}$

A large labor literature has studied the source of private-sector job-to-job mobility, and similarly we will try some characterization of regulator/private flows in the next section. That said, the mobility between private and regulator sectors is significantly smaller than that within the private sector.

\subsection{Worker Mobility as a Function of Human Capital and Seniority}

\section{Interaction with Economic Cycles}

We now study in more detail regulatory sector worker mobility by assessing which individuals enter and exit banking regulation over the business cycle as a function of their education levels and seniority in the regulatory organization. We study education levels as a proxy for human capital,

\footnotetext{
${ }^{13}$ Looking at the time variation, we see an upward trend and some pro-cyclicality of job-transitions, with transitions about 1 to 3 percent lower during recessions (consistent with previous findings, for example Shimer (2005)). While one may suspect that the upward trend could be the result of the cohort effects, we find similar patterns when conditioning to within-individual variation (that is controlling for individual fixed effects).

14 Given that we are using similar methods to match monthly observations in CPS the job-to-job transition probability for all workers that we compute in CPS is very similar to that reported in Fallick and Fleishman (2004), which report a monthly probability of $2.6 \%$ that translates into a $27.1 \%$ annual rate.

${ }^{15}$ These rates are higher than those reported in Table 1 as those summary measures are computed in terms of all individuals in the main sample, i.e., without excluding years where individuals are inactive, students or unemployed.
} 
while seniority proxies for workers' skills, connections, and importance within the organization. We explore how the sensitivity of regulatory sector transitions to economic conditions varies as a function of an individual's education and seniority by augmenting the specification in Table 2 with interaction terms. We then exploit the longitudinal properties in our sample of worker transitions to study the ability of regulators to retain key employees as measured by their higher education and seniority by characterizing the entry year of each worker into regulation and the duration of the regulatory spell as a function of his or her education and seniority.

We explore the role of education by constructing a variable, Human Capital, which is a dummy variable that takes a value of 1 for an MBA or other master's degree, a $\mathrm{PhD}$ or a $\mathrm{JD}$ and is 0 otherwise. In addition, to explore the role of seniority, which may proxy for a variety of factors such as skills and connections, we use a dummy variable, Seniority, that is equal to 1 for either senior management, high-level executive reporting to head, and head of the organization and 0 otherwise. The seniority dummy is constructed for each job title using regular expression and information from each organization; our classification covers about $90 \%$ of all titles with the remaining accounted for by idiosyncratic titles and temporary positions (for example interns, contractors, or consultants). For each individual we track the highest level of seniority while on a regulatory spell (that is, the withinworker maximum of the yearly seniority).

Table 3 shows the sensitivity of worker flows into and out of the regulatory sector to economic conditions as a function of the worker's education. We study this sensitivity by interacting the recession dummy with these indices and include individual fixed effects and trend terms as in Tables 2A/B. In addition, each index is de-meaned so that the parameter estimates on the recession dummies are the same as the un-interacted ones. 
As can be observed from column 1, the interaction term between the current recession indicator and the human capital indicator is negative but statistically insignificant. This suggests that the net flows of higher-human-capital individuals, as proxied by their educational qualification, into the regulatory sector are as sensitive to business cycle fluctuations as the net flows of their lowerhuman-capital counterparts. Columns 2 and 3 reveal similar sensitivity of worker gross inflows and outflows across different levels of worker education. These patterns are maintained when we exclude the recent financial crisis in the last three columns, and we obtain similar results when using GDP growth as an alternative measure of business cycles (unreported for brevity).

Overall, while the evidence presented in the previous section concluded that net worker flows from private sector to regulatory sector were countercyclical -- with the effects driven by gross outflows during economic booms, especially before the financial turmoil -- this effect is evident across individuals of varying human capital. Of course, higher or lower cyclicality does not predict whether higher-skilled and more senior regulatory staff outflows are higher or lower on average, an issue that we analyze next.

\section{Timing of Regulatory Spells and Retention of Talent}

To better understand the interaction of worker flows in the regulatory sector and talent, we construct two variables -- Time to first regulatory spell, which captures the time it takes for an individual to start her or his first spell in regulation from the first career activity reported on her or his CV, and Regulatory spell duration, which captures the number of years in a regulatory spell spent by an individual. In Table 4 we relate these variables to the human capital index and seniority index that we discussed earlier. For simplicity, we focus only on workers with a single regulatory spell in our sample, which cover about $97 \%$ of the whole sample. These regressions are estimated in the cross section, and as such we condition on cohort fixed effects, rather than individual fixed effects, and a 
quadratic year trend to control for potential sampling issues. We cluster the standard errors at the level of locality of the regulator.

Column 1 reveals that higher Human Capital, as captured by the highest educational qualification of an individual, predicts a later entry into regulation in an individual's career. The estimates in column 1 suggest that individuals with high Human Capital enter the regulatory sector almost 1.5 years later than those with lower degrees. This pattern, while interesting, could be somewhat mechanical since individuals who spend time acquiring human capital would tend to enter the regulatory sector later in the career.

Next, we examine the relation between seniority of regulators and the time it takes for them to enter the regulatory sector. In general, this relation could be positive or negative. On the one hand, if some senior-ranked employees are hired externally or spend more time accumulating human capital outside the regulatory sector, this relation would be positive. The reason is that such individuals would have spent more time in the private sector rising up the ranks before becoming regulators. Alternatively, if more senior-ranked regulators are promoted from within, one would expect a negative relation as these individuals would enter the regulatory sector early and then move up the ranks. Column 2 shows that the first effect is more dominant in our data -- more senior-ranked individuals tend to enter the regulatory sector almost a year later. These patterns are robust to including both the human capital index and seniority index together (column 3).

The next three columns assess the relation between human capital and seniority of regulators and the time they spend on average in regulation. The results show that individuals with higher human capital tend to have shorter spells in regulation once they enter regulation. The estimates we find are economically meaningful. For instance, estimates in column 6 suggest that individuals with high 
Human Capital tend to remain in the regulatory sector 2 years less than those with a lower human capital, which is sizable relative to a median spell duration of 6 years in regulation. We find an opposite effect of seniority: more senior regulators tend to have longer spells. This may not be very surprising since we pick the highest level in the regulatory organization for each worker, and the rank will tend to be higher for more seasoned workers.

While patterns with seniority may be hard to interpret because of the higher probability that employees with longer spells raise through the ranks of an organization, the evidence in terms of human capital suggests that regulators face some retention challenges. The best talent, as proxied by higher human capital (and seniority in regulatory organization) takes longer to enter the regulatory sector and spends less time in the regulatory sector before switching to the private sector.

One concern in interpreting our findings regarding the length of the regulatory spell is that any temporal spell in our data suffers from right truncation because we can only observe the data through the end of our sample. To address potential truncation issues, we use an alternative approach and analyze how the fraction of regulators with medium to long regulatory spells -- either more than three years or more than five years - evolved as a function of worker characteristics and over time. In particular, in Table 5, we estimate a cross-sectional regression where the dependent variable is an indicator variable, Spell, which is equal to 1 if the regulatory spell of a given regulator was more than three years (columns 1 to 4 ) or five years (columns 5 to 8 ). To guard against data truncation towards the end of the sample we end our sample in the year 2010 (2008) when studying the share of workers with at least three (five) year spells. The main explanatory variable is Start, which measures the first year in regulation for a given regulator since 1988 (that is, this variable is normalized to zero in 1998). 
Focusing on the three-year spells first, we observe that, on average, regulators have a roughly $71 \%$ probability of spending three years or more in regulation (column 1). In other words, about $71 \%$ of the workers in our sample had a regulatory spell of more than three years. Consistent with the results in Table 4, higher human capital workers are less likely to stay in regulation for more than three years, and the opposite is true for more senior workers (column 2). There is a large decline in the likelihood of spending three years or longer in regulation for all the workers (column 3). While, on average, about $88 \%$ of workers that started working in regulation in 1988 spent three years or more in regulation, only $64 \%(.884-20 * .012)$ of workers that started working two decades later did so. These patterns remain when we control for human capital and seniority levels (column 4) and when studying workers with job spells that are at least five years long. These findings reiterate presence of retention issues in the regulatory sector for employees with the highest levels of human capital, and also suggest retention issues may have indeed worsened for all employees over the past few years as measured by the fraction of workers with short employment spells in the regulatory sector.

\section{Transitions and Enforcement Actions: “Quid-Pro-Quo” \& "Regulatory Schooling” Hypotheses}

Regulatory transitions are often scrutinized because of the quid-pro-quo channel according to which future employment opportunities in the private sector may affect the strictness of actions of regulatory personnel. This hypothesis implies that we should observe low gross outflows from regulation to private banking during periods of high enforcement activity. According to a different view (the "regulatory schooling” view), regulators may have an incentive to favor excessively complex regulations or strict enforcement activity because the "schooling" in regulations enhances the expected future earnings of regulators, should they move to the private sector. While empirically enforcement actions do not measure regulatory complexity, the ultimate impact of a rule is the result of both regulations and the manner in which these are enforced through supervision (see Agarwal et al., 2014 on these points). Thus, based on the schooling view, we should observe higher gross inflows into regulation at times of higher regulatory intensity, as workers are schooled, as well as 
contemporaneous or subsequent high gross outflows from regulation to private sector as these workers earn the return from regulatory schooling. In this section we study whether these channels may be driving fluctuations in regulatory worker transitions beyond the cyclical patterns that we have uncovered so far. More specifically, we test whether variation in regulatory enforcement activity is related to the frequency with which we observe regulatory personnel transitioning into and out of private sector employment over time and in the cross-section of states.

The central challenge in testing such a link is the measurement of regulatory enforcement activity. We measure such activity using the frequency of public enforcement actions both because of their availability and their key importance in supervisory activity. As discussed in Agarwal et al (2014), regulators use onsite examination to audit bank conditions and assign confidential regulatory ratings based on their findings on a scale from one to five. Banks with a rating of 1 or 2 are considered to present few (if any) significant regulatory concerns, whereas those rated 3 and above present moderate to extreme levels of regulatory concerns. When problems are uncovered at exams, regulators use enforcement actions to communicate problems and weaknesses to banks and require them to take corrective actions (see, for example, OCC Policies and Procedures Manual 5310-3). When a bank is in good standing (i.e. a rating of 1 or 2), regulators typically use informal enforcement actions, which are not disclosed to the public, such as memoranda of understanding and commitment letters. Formal actions are instead disclosed to the public, are much more severe, and their use is often mandated for banks rated 3 or above.

We collect all enforcement orders and actions of banking regulators in our sample period from the Fed, the FDIC, the OCC, and the OTS. Formal enforcement actions include prohibition and removal orders, civil money penalties, formal agreements, cease and desist (C\&D) orders, prompt corrective 
action (PCA) directives, and terminations or suspensions of deposit insurance. ${ }^{16}$ Because each action may in principle be of different severity and it is not possible to rank all of these actions on an objective scale, we focus on a set of formal actions that are similar in their severity. We first exclude civil penalties and prohibition and removal orders, because these actions are generally taken against individuals and for law violation rather than for safety and soundness of a bank. Further, we exclude formal agreements, which are bilateral documents signed by the bank and regulators, which, unlike C\&D orders and PCA directives, are not enforceable in the federal court system. C\&D orders are used to impose corrective action on a bank for example by restricting a bank's growth and forcing disposal of assets. Similarly PCA directives impose mandatory restrictions on a banks’ activity as a function of its capital levels. Failure to comply with C\&D orders and PCA directives and actions on deposit insurance are all grounds for receivership. Accordingly, we focus on the intensity of these enforcement orders by regulators on institutions in their geographical jurisdiction as an indicator of regulatory strictness.

In Table 6 we use specifications similar to those employed in Table 2A and Table $2 \mathrm{~B}$ to examine whether movement of an individual in and out of the regulatory sector is related to the intensity of formal enforcement orders by that individual's regulatory agency in a given state and year. In the

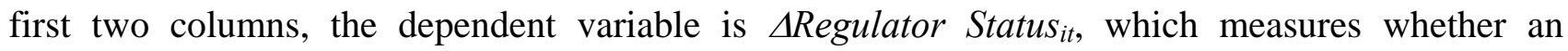
individual is employed in the regulatory sector this year relative to the prior year. In columns 3 and 4 we run analogous regressions, using the dummy for inflow and outflow as defined in Table $2 \mathrm{~B}$. As was the case in previous specifications, the regressions include individual fixed effects and time controls to account for unobserved characteristics and potential sampling distortions. In terms of time controls we either use quadratic trends and a NBER recession dummy as in prior specifications

\footnotetext{
${ }^{16}$ We restrict this information to that reported by federal banking regulators because information for state regulators is not standardized and is difficult to collect. That said, because state regulators supervise state chartered banks jointly with the FDIC and the Fed, and many of these enforcement actions are taken jointly by the two regulators, our sample includes information on state regulators' actions as well.
} 
(odd columns) or, given that enforcement actions also have cross-state variation, time dummies (even columns). The main explanatory variable is Enforcement Actions, which measures the total enforcement actions as discussed above that are issued by her or his agency in the state and year of location of that individual.

On net, we find a positive association between the intensity of strict actions and the net movement into the regulatory sector in the full sample (column 1). Importantly, in column 2, we show that this relation survives inclusion of time fixed effects. This implies that the positive association between regulator activity and net inflows is identified even when we use variation across states and regulators and is not just capturing aggregate economic conditions. Next, we drill down into these patterns by examining the relation between intensity of enforcement and gross inflows (columns 3 and 4) and outflows (columns 5 and 6) from the regulatory sector into the private sector. Several patterns emerge from this analysis. First, the results established in the first two columns are driven largely by inflows of individuals into regulatory jobs around periods of or for regulators in states with high enforcement activity rather than outflows. This can be clearly seen if we compare the magnitude of estimates on enforcement variables in column $3(0.245)$ with estimates on these variables in column 5 (0.04). The estimates in column 3 suggest about 12\% higher inflows into the regulatory sector, relative to the within-individual standard deviation of inflows, around periods of one-standard-deviation higher enforcement activity in a given state. In other words, the relationship between high enforcement intensity and flows into the regulatory sector is driven by a surge of inflows around periods of high regulatory activity. This pattern is inconsistent with the quid-pro-quo channel where outflows should be the dominant factor. Second, setting aside the relative absolute magnitude of inflows and outflows, the sign on the outflow term (column 5) is also not consistent with the quid-pro-quo channel since we find more outflow from the regulatory sector around periods of higher enforcement activity. We find similar results when controlling for time effects (columns 4 
and 6) or when we proxy for economic condition with real GDP growth rather than with the NBER recession dummy.

The evidence on gross flows and intensity of regulatory activity is, instead, broadly consistent with the regulatory school view. High gross inflows into regulation during times of regulatory intensity may reflect workers moving into regulatory sector to get schooled in the new complexity. As well, gross flows from regulation to private sector may reflect regulators' increased incentives to earn returns from regulatory schooling at times of higher enforcement activity when their regulatory human capital becomes more valuable. These patterns are consistent with Agarwal et al. (2014) who find higher turnover of state regulators into private sector if these regulators give harsher supervisory ratings to banks under their supervision.

In sum, we find that based on our measures, the patterns in overall aggregate transitions of regulatory personnel over time and across states are opposite of what would be implied by a quid pro quo story and are instead broadly consistent with the regulatory schooling story. This evidence is admittedly naïve and not a ubiquitous test of the quid-pro-quo or regulatory schooling hypothesis. Moreover, it cannot rule out the presence of distortions in banking regulations at a more microeconomic level or that regulations may be more complex as a result of the schooling hypothesis (see Shive and Forster (2014) for a step in this direction).

\section{Conclusion}

In the aftermath of the financial crisis, job transitions of regulatory personnel between the regulatory and private sector have come under intense scrutiny and have been blamed by economists (Johnson and Kwak 2010), legal scholars (John Coffee in Financial Times [April 23, 2012]) and policymakers (Dodd-Frank Act, Section 968) alike for distorting government regulators' actions on behalf of industry interests. Because of the difficulty in obtaining data, the general perception driving these 
discussions are informed by anecdotes, which are often linked to former regulatory personnel transitioning to the private sector around apparent regulatory failures.

This paper presents a novel data set tracing the career transitions of a large sample of former and current banking regulators in and out of the private sector. Based on this data, we find that similar to worker transitions in other industries, worker flows between the regulatory and private sector in banking can also be characterized in terms of standard demand and supply factors in the two sectors. Workers enter regulation in tough economic conditions, likely due to its relative attractiveness at these times, and in periods of financial distress, when job creation in the regulatory sector and job destruction in the private sector are at their peaks. Overall the mobility of regulatory workers is lower than their private-sector counterparts.

The evidence on higher gross inflows and outflows during periods of more intense regulatory activity are consistent with the regulatory school view. According to this view, workers may move into the regulatory sector to get schooled in the new complexity and then move from regulation to the private sector to earn the returns from regulatory schooling at times of higher enforcement activity when their regulatory human capital may be more valuable. The evidence is inconsistent with the quid-pro-quo channel driving variation in aggregate worker flows between the regulatory and private sector in banking. Our tests on this dimension are limited due to availability of regulator specific proxies of enforcement activity or of regulatory complexity. We therefore caution against taking these findings as establishing a conclusive assessment of whether quid-pro-quo or regulatory schooling leads to regulatory distortions.

More broadly, our findings speak to the debate on the design of rules concerning revolving doors. Critics of the regulatory revolving door have proposed restricting the ability of regulatory personnel to transition to the private sector, which under federal law (see 12 U.S.C. $§ 1820(\mathrm{k})$ ) is subject to a 
one-year “cool-off” period for any compensation -- as an employee, officer, director, or consultant -with a previously supervised institution. There have also been discussions to further tighten the hiring of industry insiders by regulatory agencies. Such arguments, while no doubt important, ignore other important positive aspects of the revolving door, such as its potential to enhance the ability of regulatory agencies to hire better quality workers. Our results suggest that the regulatory sector faces a retention challenge, as measured by the lower employment spells of regulatory personnel in more recent years and for workers with higher education. While more work is needed to quantify the regulatory distortions induced by the revolving door, our findings do suggest that tightening the revolving door without altering other aspects of worker incentives may further create challenges for regulatory agencies to seek and retain talent.

\section{References}

Agarwal, Sumit, David Lucca, Amit Seru, and Francesco Trebbi, 2014, "Inconsistent Regulators: Evidence from Banking”, Quarterly Journal of Economics, forthcoming.

Artuç, Erhan, Shubham Chaudhuri, and John McLaren. 2010. "Trade Shocks and Labor Adjustment: A Structural Empirical Approach." American Economic Review, 100(3): 1008-45.

Barth, James, Gerard Caprio, and Ross Levine, 2004, "Bank Regulation and Supervision: What Works Best?” Journal of Financial Intermediation 13, 205-248.

Berger, Allen N., and Timothy H. Hannan, 1998, "The efficiency cost of market power in the banking industry: A test of the 'quiet life' and related hypotheses," Review of Economics and Statistics, Vol. 80, No. 3, August, pp. 454-465.

Besley, Tim and Stephen Coate, 2003. "Elected Versus Appointed Regulators: Theory and Evidence” Journal of the European Economic Association, 5(9), pp 1176-1206.

Betrand, Marianne, Matilde Bombardini, and Francesco Trebbi. 2013 "Is It Whom You Know or What You Know? An Empirical Assessment of the Lobbying Process” NBER WP 16765.

Blanchard, Olivier J. and Peter Diamond 1990. "The Cyclical Behavior of the Gross Flows of U.S. Workers, ” Brookings Papers on Economic Activity 2, 85-155.

Blanes I Vidal, Jordi; Draca, Mirko; Fons-Rosen, Christian; 2012. "Revolving Door Lobbyists" American Economic Review, Volume 102, Number 7, pp. 3731-3748(18).

Cohen, Jeffrey E. 1986 "The Dynamics of the "Revolving Door" on the FCC” American Journal of Political Science, Vol. 30, No. 4, pp. 689-708. 
Davis, Steve, Faberman, Jason, and John Haltiwanger "The Flow Approach to Labor Markets: New Data Sources and Micro-Macro Links.” Journal of Economic Perspectives, Summer 2006.

deHaan, Ed and Kedia, Simi and Koh, Kevin and Rajgopal, Shivaram, 2012 "Does the Revolving Door Affect the SEC’s Enforcement Outcomes?” mimeo Stanford University.

Diermeier, Daniel, Michael Keane, and Antonio Merlo. 2005. "A Political Economy Model of Congressional Careers" American Economic Review, 95(1): 347-373.

Fallick, Bruce and Charles A. Fleischman 2004. "Employer-to-Employer Flows in the U.S. Labor Market: The Complete Picture of Gross Worker Flows,” FEDS Working Papers 2004-34, Federal Reserve Board.

Gormley, William. 1979. “A test of the revolving door hypothesis on the FCC”. American Journal of Political Science, 23:665-83.

Hall, Robert E. 2006. "Job loss, job finding and unemployment in the US economy over the past 50 years”, NBER Macroeconomics Annual 2005.

Johnson Simon and James Kwak 2010. "13 Bankers: The Wall Street Takeover and the Next Financial Meltdown," Published by Random House Inc.

Kroszner, Randall S., and Philip E. Strahan, 1999. "What Drives Deregulation? Economics and Politics of the Relaxation of Bank Branching Restrictions,” Quarterly Journal of Economics, Vol. 114, No. 4, November, pp. 1437-1467.

Loungani, Prakash, and Richard Rogerson. "Cyclical fluctuations and sectoral reallocation: evidence from the PSID." Journal of Monetary Economics 23.2 (1989): 259-273.

Moore, Jeffrey C, 2008 "Seam Bias in the 2004 SIPP panel: much improved, but much bias still remains." US Census Bureau Statistical Research Division Survey Methodology Research Report Series 3 (2008): 2008.

Nagypál, Éva, 2008 "Worker reallocation over the business cycle: The importance of job-to-job transitions.” mimeo, Northwestern University

Mukoyama Toshihiko (2013) "The Cyclicality of Job-to-Job Transitions and its Implications for Aggregate Productivity.” Working paper.

Salant, D. 1995. "Behind the Revolving Door: A New View of Public Utility Regulation." RAND Journal of Economics, Vol. 26, pp. 362-377.

Shimer, Robert 2005. “The Cyclicality of Hires, Separations, and Job-to-job Transitions” Federal Reserve Bank of St. Louis Review 87(4), 493-507.

Shimer, Robert 2012. "Reassessing the ins and outs of unemployment." Review of Economic Dynamics 15.2: 127-148.

Shive, Sophie and Margaret Forester 2014. “The Revolving door for financial regulators.” Working paper 


\section{Table 1: Summary Statistics}

This table presents summary statistics for the main variables of interest, split by whether these measures are used in a panel (1A) or cross-section analysis (1B). Sample period is 1988-2013.

Panel A: Variables used in Panel Regressions

\begin{tabular}{lccccc}
\hline \hline & $(1)$ & $(2)$ & $(3)$ & $(4)$ & $(5)$ \\
\cline { 2 - 6 } & $\mathrm{N}$ & Mean & SD & Min & Max \\
\cline { 2 - 6 } ARegulator Status & 555,139 & 0.013 & 0.27 & -1 & 1 \\
Into Reg Status & 555,139 & 0.042 & 0.20 & 0 & 1 \\
Out of Reg Status & 555,139 & 0.029 & 0.17 & 0 & 1 \\
Recession Indicator & 555,139 & 0.13 & 0.28 & 0 & 1 \\
Real GDP & 527,574 & 2.45 & 1.80 & -2.80 & 4.85 \\
Enforcement Actions & 411,404 & 0.023 & 0.068 & 0 & 0.65 \\
Human Capital & 555,139 & 0.45 & 0.50 & 0 & 1 \\
Seniority & 482,442 & 0.11 & 0.32 & 0 & 1 \\
ROA & 482,916 & 0.0073 & 0.0060 & -0.029 & 0.055 \\
\% Non-performing loans & 482,916 & 0.016 & 0.015 & 0.001 & 0.12 \\
Total Bank Failures & 532,807 & 0.032 & 0.14 & 0 & 1.97 \\
\hline \hline
\end{tabular}

Panel B: Variables used in Cross-sectional Regressions

\begin{tabular}{lccccc}
\hline \hline & $(1)$ & $(2)$ & $(3)$ & $(4)$ & $(5)$ \\
\cline { 2 - 6 } & $\mathrm{N}$ & Mean & SD & Min & Max \\
\cline { 2 - 6 } Time to first regulatory spell & 24,543 & 9.57 & 9.06 & 0 & 56 \\
Regulatory spell duration & 29,774 & 6.72 & 7.41 & 1 & 53 \\
Human Capital & 29,774 & 0.43 & 0.49 & 0 & 1 \\
Seniority & 25,235 & 0.096 & 0.29 & 0 & 1 \\
\hline \hline
\end{tabular}




\section{Table 2: Economic Cycles and Regulatory-Private Sector Worker flows}

This table reports estimates from regressions of net worker flows into regulatory sector and gross inflows and outflows on business cycle measures. In Panel A, the dependent variable is $\Delta$ Regulator Status $s_{i t}$ which measures for each individual $i$ transitions in and out of employment in the regulatory sector between year $t-1$ and $t$. The main explanatory variables are current and lagged values of a Recession Indicator, which measures the number of months each year that have been classified by the NBER as being part of a recession. In last column Real GDP growth is annual real GDP growth rate in percent. Panels B and C show estimates analogous to Panel A but also use gross inflows and gross outflows from regulatory sector as the dependent variables. Into Reg Status (Out of Reg Status $_{i t}$ ) is a dummy that takes a value 1 if the individual $i$ leaves a private (regulatory) job in year $t-1$ for a regulatory (private) job in year $t$.and is 0 otherwise. Controls include a quadraticpolynomial in the calendar year and cohort fixed effects. In the individual fixed effects analysis we drop the cohort effects, as these are spanned by the individual effects. Standard errors clustered at the locality level. *** significant at $1 \%$ level. ** significant at $5 \%$ level. * significant at $10 \%$ level.

Panel A: Net Worker Flows into Regulatory Sector

\begin{tabular}{|c|c|c|c|c|c|c|}
\hline & $(1)$ & $(2)$ & $(3)$ & $(4)$ & (5) & $(6)$ \\
\hline & \multicolumn{6}{|c|}{$\Delta$ Regulator Status } \\
\hline Recession Indicator $r_{t}$ & $\begin{array}{c}0.020 * * * \\
{[0.003]}\end{array}$ & $\begin{array}{c}0.014^{* * *} \\
{[0.002]}\end{array}$ & $\begin{array}{c}0.013^{* * *} \\
{[0.002]}\end{array}$ & $\begin{array}{c}0.013 * * * \\
{[0.002]}\end{array}$ & $\begin{array}{c}0.019 * * * \\
{[0.003]}\end{array}$ & \\
\hline Recession Indicator $r_{t-1}$ & & $\begin{array}{c}0.030 * * * \\
{[0.004]}\end{array}$ & $\begin{array}{c}0.027 * * * \\
{[0.004]}\end{array}$ & $\begin{array}{c}0.027 * * * \\
{[0.004]}\end{array}$ & $\begin{array}{c}0.011^{* * *} \\
{[0.002]}\end{array}$ & \\
\hline Real $G D P_{t}$ & & & & & & $\begin{array}{c}-0.004 * * * \\
{[0.001]}\end{array}$ \\
\hline Real $G D P_{t-1}$ & & & & & & $\begin{array}{c}-0.002^{* *} \\
{[0.001]} \\
\end{array}$ \\
\hline Observations & 555,139 & 555,139 & 555,139 & 555,139 & 359,059 & 527,574 \\
\hline R-squared & 0.000 & 0.001 & 0.005 & 0.026 & 0.038 & 0.029 \\
\hline Individual FE & No & No & No & Yes & Yes & Yes \\
\hline Other Controls & No & No & $\begin{array}{c}\text { Quad.Trend } \\
\text { and Cohort FEs }\end{array}$ & Quad.Trend & Quad.Trend & Quad.Trend \\
\hline Sample & 1988-2013 & $1988-2013$ & $1988-2013$ & 1988-2013 & 1988-2006 & 1988-2012 \\
\hline N Individuals & 29734 & 29734 & 29734 & 29734 & 26926 & 29658 \\
\hline Within Mean & & & & 0.0210 & 0.0110 & 0.0232 \\
\hline Within SD & & & & 0.147 & 0.183 & 0.157 \\
\hline
\end{tabular}


Table 2: Economic Cycles and Regulatory-Private Sector Worker flows (contd.)

Panel B: Gross Worker Flows into and out of Regulatory Sector

\begin{tabular}{|c|c|c|c|c|c|c|}
\hline & (1) & (2) & (3) & (4) & (5) & (6) \\
\hline & Into Reg Status & Out of Reg Status & Into Reg Status & Out of Reg Status & Into Reg Status & Out of Reg Status \\
\hline Recession Indicator $_{t}$ & $\begin{array}{c}0.006^{* * *} \\
{[0.002]}\end{array}$ & $\begin{array}{c}-0.008 * * * \\
{[0.001]}\end{array}$ & $\begin{array}{c}0.008 * * * \\
{[0.002]}\end{array}$ & $\begin{array}{c}-0.011^{* * *} \\
{[0.002]}\end{array}$ & & \\
\hline Recession Indicator $_{t-1}$ & $\begin{array}{c}0.019 * * * \\
{[0.004]}\end{array}$ & $\begin{array}{c}-0.008^{* * *} \\
{[0.001]}\end{array}$ & $\begin{array}{c}-0.005^{* *} \\
{[0.002]}\end{array}$ & $\begin{array}{c}-0.016^{* * *} \\
{[0.001]}\end{array}$ & & \\
\hline Real $G D P_{t}$ & & & & & $\begin{array}{l}-0.001 * \\
{[0.001]}\end{array}$ & $\begin{array}{c}0.003^{* * *} \\
{[0.000]}\end{array}$ \\
\hline Real $G D P_{t-1}$ & & & & & $\begin{array}{c}-0.001 \\
{[0.001]} \\
\end{array}$ & $\begin{array}{c}0.001 * * * \\
{[0.000]}\end{array}$ \\
\hline Observations & 555,139 & 555,139 & 359,059 & 359,059 & 527,574 & 527,574 \\
\hline R-squared & 0.035 & 0.039 & 0.060 & 0.052 & 0.042 & 0.042 \\
\hline Individual FE & Yes & Yes & Yes & Yes & Yes & Yes \\
\hline Other Controls & Quad.Trend & Quad.Trend & Quad.Trend & Quad.Trend & Quad.Trend & Quad.Trend \\
\hline Sample & $1988-2013$ & $1988-2013$ & 1988-2006 & 1988-2006 & 1988-2012 & 1988-2012 \\
\hline N Individuals & 29734 & 29734 & 26926 & 26926 & 29658 & 29658 \\
\hline Within Mean & 0.0561 & 0.0351 & 0.0354 & 0.0244 & 0.0587 & 0.0355 \\
\hline Within SD & 0.127 & 0.133 & 0.147 & 0.130 & 0.136 & 0.135 \\
\hline
\end{tabular}


Table 2: Economic Cycles and Regulatory-Private Sector Worker flows (contd.)

Panel C: Sources of Worker Flows into and out of Regulatory Sector

\begin{tabular}{|c|c|c|c|c|c|c|}
\hline & $(1)$ & $(2)$ & (3) & (4) & (5) & (6) \\
\hline & \multicolumn{2}{|c|}{$\Delta$ Regulator Status } & \multicolumn{2}{|c|}{ Into Reg Status } & \multicolumn{2}{|c|}{ Out of Reg Status } \\
\hline Recession Indicator $_{t}$ & $\begin{array}{c}0.010^{* * *} \\
{[0.003]}\end{array}$ & $\begin{array}{c}0.009 * * * \\
{[0.003]}\end{array}$ & $\begin{array}{c}-0.000 \\
{[0.002]}\end{array}$ & $\begin{array}{c}-0.000 \\
{[0.002]}\end{array}$ & $\begin{array}{c}-0.010^{* * *} \\
{[0.001]}\end{array}$ & $\begin{array}{c}-0.010^{* * *} \\
{[0.001]}\end{array}$ \\
\hline$R O A_{t}$ & $\begin{array}{c}-0.827 * * * \\
{[0.237]}\end{array}$ & $\begin{array}{c}-0.366 \\
{[0.242]}\end{array}$ & $\begin{array}{c}-0.354 * \\
{[0.204]}\end{array}$ & $\begin{array}{c}-0.078 \\
{[0.212]}\end{array}$ & $\begin{array}{c}0.473^{* * *} \\
{[0.123]}\end{array}$ & $\begin{array}{l}0.288^{*} \\
{[0.147]}\end{array}$ \\
\hline$\%$ Non-performing loans ${ }_{t}$ & & $\begin{array}{c}0.289 * * * \\
{[0.087]}\end{array}$ & & $\begin{array}{c}0.164 * * \\
{[0.078]}\end{array}$ & & $\begin{array}{c}-0.125^{* *} \\
{[0.056]}\end{array}$ \\
\hline Total Bank Failures & & $\begin{array}{c}0.035 * * \\
{[0.016]}\end{array}$ & & $\begin{array}{c}0.023^{*} \\
{[0.013]}\end{array}$ & & $\begin{array}{c}-0.012^{* * *} \\
{[0.004]} \\
\end{array}$ \\
\hline Observations & 482,916 & 482,916 & 482,916 & 482,916 & 482,916 & 482,916 \\
\hline R-squared & 0.031 & 0.032 & 0.046 & 0.046 & 0.045 & 0.045 \\
\hline Individual FE & Yes & Yes & Yes & Yes & Yes & Yes \\
\hline Other Controls & Quad.Trend & Quad.Trend & Quad.Trend & Quad.Trend & Quad.Trend & Quad.Trend \\
\hline Sample & $1990-2012$ & 1990-2012 & 1990-2012 & 1990-2012 & 1990-2012 & $1990-2012$ \\
\hline N Individuals & 28691 & 28691 & 28691 & 28691 & 28691 & 28691 \\
\hline Within Mean & 0.0232 & 0.0232 & 0.0588 & 0.0588 & 0.0356 & 0.0356 \\
\hline Within SD & 0.161 & 0.161 & 0.141 & 0.141 & 0.138 & 0.138 \\
\hline
\end{tabular}




\section{Table 3: Economic Cycles and Regulatory-Private Sector Worker flows as a function of Human Capital}

This table reports estimates from regressions of net worker flows into regulatory sector and gross inflows and outflows on business cycle conditions. The explanatory variables include interaction of Human Capital (a value 1 implying more educational qualification) with the current value of a Recession Indicator, which measures the number of months each year that have been classified by the NBER as being part of a recession. Additional controls are quadratic-polynomial in the calendar year and individual fixed effects. Standard errors clustered at the locality level. *** significant at $1 \%$ level. $* *$ significant at $5 \%$ level. * significant at $10 \%$ level.

\begin{tabular}{|c|c|c|c|c|c|c|}
\hline & $(1)$ & $(2)$ & $(3)$ & $(4)$ & $(5)$ & $(6)$ \\
\hline & $\Delta$ Regulator Status & Into Reg Status & Out of Reg Status & $\Delta$ Regulator Status & Into Reg Status & Out of Reg Status \\
\hline \multirow[t]{2}{*}{ Recession Indicator $_{t}$} & $0.0186^{* * *}$ & $0.0093 * * *$ & $-0.0093 * * *$ & $0.0187 * * *$ & $0.0081 * * *$ & $-0.0106 * * *$ \\
\hline & {$[0.0029]$} & {$[0.0025]$} & {$[0.0010]$} & {$[0.0033]$} & {$[0.0024]$} & {$[0.0015]$} \\
\hline \multirow[t]{2}{*}{ Human Capital Index* Recession Indicator ${ }_{t}$} & -0.0002 & 0.0013 & 0.0016 & -0.0024 & -0.0026 & -0.0003 \\
\hline & {$[0.0031]$} & {$[0.0022]$} & {$[0.0019]$} & {$[0.0046]$} & {$[0.0034]$} & {$[0.0029]$} \\
\hline Observations & 555,139 & 555,139 & 555,139 & 359,059 & 359,059 & 359,059 \\
\hline R-squared & 0.025 & 0.035 & 0.039 & 0.038 & 0.060 & 0.051 \\
\hline Individual FE & Yes & Yes & Yes & Yes & Yes & Yes \\
\hline Other Controls & Quad.Trend & Quad.Trend & Quad.Trend & Quad.Trend & Quad.Trend & Quad.Trend \\
\hline Sample & 1988-2013 & 1988-2013 & 1988-2013 & 1988-2006 & 1988-2006 & 1988-2006 \\
\hline N Individuals & 29734 & 29734 & 29734 & 26926 & 26926 & 26926 \\
\hline Within Mean & 0.0210 & 0.0561 & 0.0351 & 0.0110 & 0.0354 & 0.0244 \\
\hline Within SD & 0.147 & 0.127 & 0.133 & 0.183 & 0.147 & 0.130 \\
\hline
\end{tabular}




\section{Table 4: Time to first Regulatory spell and Regulatory spell duration as a function of Human Capital and Seniority}

This table reports estimates from regressions that relate the time it takes an individual to enter the regulatory sector and the years spent on average in regulation to human capital and seniority indices we constructed earlier. The main dependent variable in the first three columns is Time to first regulatory spell, which captures the time it takes for an individual to start their first spell in regulation from their first career activity reported on their CV. In the last three columns, the dependent variable is Regulatory spell duration, which captures the number of years in a regulatory spell spent by an individual. The main explanatory variables are indicator variables, Human Capital (a value of 1 implying more educational qualification) and Seniority (a value of 1 implying higher rank in the regulatory organization) Controls include a quadratic-polynomial in the calendar year and cohort fixed effects. Standard errors clustered at the locality level. *** significant at $1 \%$ level. $* *$ significant at 5\% level. * significant at $10 \%$ level.

\begin{tabular}{|c|c|c|c|c|c|c|}
\hline & $(1)$ & $(2)$ & (3) & (4) & (5) & (6) \\
\hline & \multicolumn{3}{|c|}{ Time to first regulatory spell } & \multicolumn{3}{|c|}{ Regulatory spell duration } \\
\hline \multirow[t]{2}{*}{ Human Capital } & $1.570 * * *$ & & $1.513 * * *$ & $-2.000 * * *$ & & $-2.321 * * *$ \\
\hline & {$[0.194]$} & & {$[0.203]$} & {$[0.117]$} & & {$[0.130]$} \\
\hline \multirow[t]{2}{*}{ Seniority } & & $0.808 * * *$ & $0.578 *$ & & $3.900 * * *$ & $4.253 * * *$ \\
\hline & & {$[0.312]$} & {$[0.302]$} & & {$[0.374]$} & {$[0.361]$} \\
\hline Observations & 23,708 & 20,902 & 20,902 & 28,910 & 24,412 & 24,412 \\
\hline R-squared & 0.233 & 0.218 & 0.225 & 0.177 & 0.166 & 0.190 \\
\hline Year and Cohort FEs & Yes & Yes & Yes & Yes & Yes & Yes \\
\hline Sample & 1988-2013 & 1988-2013 & 1988-2013 & 1988-2013 & 1988-2013 & 1988-2013 \\
\hline
\end{tabular}




\section{Table 5: Regulatory Spells over time}

This table reports estimates from regressions that analyze how the fraction of regulators with medium to long tenures (either more than three or more than five years) has changed as the private financial sector has expanded over time. The dependent variable is a dummy variable, Spell, that indicates whether the regulatory spell of a given regulator was more than three years (columns 1 to 4) or five years (columns 5 to 8). The main explanatory variable is Start, which measures the first year in regulation for a given regulator, starting in 1988 (that is, this variable is normalized to zero in 1998). Other explanatory variables include indicator variables, Human Capital (a value of 1 implying more educational qualification) and Seniority (a value of 1 implying higher rank in the regulatory organization) Standard errors clustered at the locality level. *** significant at $1 \%$ level. ${ }^{* *}$ significant at $5 \%$ level. * significant at $10 \%$ level.

\begin{tabular}{|c|c|c|c|c|c|c|c|c|}
\hline & $(1)$ & $(2)$ & (3) & (4) & $(5)$ & $(6)$ & $(7)$ & $(8)$ \\
\hline & \multicolumn{4}{|c|}{$\mathrm{I}($ Spell of more than 3 years $=1)$} & \multicolumn{4}{|c|}{$\mathrm{I}($ Spell of more than 5 years $=1)$} \\
\hline \multirow[t]{2}{*}{ Start } & & & $-0.012 * * *$ & $-0.009 * * *$ & & & $-0.008 * * *$ & $-0.004 * * *$ \\
\hline & & & {$[0.000]$} & {$[0.000]$} & & & {$[0.001]$} & {$[0.001]$} \\
\hline \multirow[t]{2}{*}{ Human Capital } & & $-0.053 * * *$ & & $-0.049 * * *$ & & $-0.116^{* * *}$ & & $-0.113^{* * *}$ \\
\hline & & {$[0.007]$} & & {$[0.007]$} & & [0.009] & & {$[0.009]$} \\
\hline \multirow[t]{2}{*}{ Seniority } & & $0.180 * * *$ & & $0.169 * * *$ & & $0.281 * * *$ & & $0.278^{* * *}$ \\
\hline & & {$[0.008]$} & & {$[0.008]$} & & {$[0.012]$} & & {$[0.012]$} \\
\hline \multirow[t]{2}{*}{ Constant } & $0.712^{* * *}$ & $0.764 * * *$ & $0.884 * * *$ & $0.881^{* * *}$ & $0.565^{* * *}$ & $0.617 * * *$ & $0.654^{* * *}$ & $0.665^{* * *}$ \\
\hline & [0.003] & {$[0.004]$} & {$[0.006]$} & {$[0.007]$} & {$[0.004]$} & {$[0.006]$} & {$[0.008]$} & {$[0.009]$} \\
\hline Observations & 19,449 & 16,501 & 19,449 & 16,501 & 15,031 & 13,056 & 15,031 & 13,056 \\
\hline R-squared & 0.000 & 0.017 & 0.038 & 0.038 & 0.000 & 0.039 & 0.010 & 0.042 \\
\hline Sample & $1988-2010$ & $1988-2010$ & $1988-2010$ & $1988-2010$ & 1988-2008 & 1988-2008 & $1988-2008$ & 1988-2008 \\
\hline
\end{tabular}




\section{Table 6: Formal Enforcement actions and Regulatory-Private Sector Worker flows}

This table reports estimates from regressions that examine whether movements of an individual in and out of the regulatory sector are related to the intensity of formal enforcement orders by that individual's regulatory agency. In the first two columns, the dependent variable is $\Delta$ Regulator Status ${ }_{i t}$, which measures whether an individual is employed in the regulatory sector this year relative to the prior year. In columns 3 to 6 we run analogous regressions, using Into Reg Status ${ }_{i t}$ and Out of Reg Status it as dependent variables. The main explanatory variable is current Enforcement Actions, which captures the total formal enforcement orders pertaining to cease and desist orders, prompt corrective action directives and actions on deposit insurance that are issued by a regulator's agency in the state and year of location of that regulator. All regression specifications include individual fixed effects, quadratic trends and NBER recession dummies. Standard errors clustered at the locality level. *** significant at $1 \%$ level. ** significant at $5 \%$ level. * significant at $10 \%$ level.

\begin{tabular}{|c|c|c|c|c|c|c|}
\hline \multirow{4}{*}{ Enforcement Actions ${ }_{t}$} & $(1)$ & $(2)$ & (3) & $(4)$ & $(5)$ & $(6)$ \\
\hline & \multicolumn{2}{|c|}{$\Delta$ Regulator Status } & \multicolumn{2}{|c|}{ Into Reg Status } & \multicolumn{2}{|c|}{ Out of Reg Status } \\
\hline & $0.205^{* * *}$ & $0.181^{* * *}$ & $0.245 * * *$ & $0.216 * * *$ & $0.040 * * *$ & $0.035 * * *$ \\
\hline & {$[0.039]$} & {$[0.042]$} & {$[0.044]$} & {$[0.045]$} & {$[0.013]$} & {$[0.012]$} \\
\hline \multirow[t]{2}{*}{ Recession Indicator $_{t}$} & $0.018 * * *$ & & $0.008 * * *$ & & $-0.010 * * *$ & \\
\hline & {$[0.003]$} & & {$[0.003]$} & & {$[0.001]$} & \\
\hline Observations & 411,404 & 411,404 & 411,404 & 411,404 & 411,404 & 411,404 \\
\hline R-squared & 0.029 & 0.031 & 0.041 & 0.045 & 0.041 & 0.044 \\
\hline Individual FE & Yes & Yes & Yes & Yes & Yes & Yes \\
\hline Other Controls & Quad.Trend & Year FEs & Quad.Trend & Year FEs & Quad.Trend & Year FEs \\
\hline Sample & 1990-2013 & 1990-2013 & 1990-2013 & 1990-2013 & 1990-2013 & 1990-2013 \\
\hline N Individuals & 22881 & 22881 & 22881 & 22881 & 22881 & 22881 \\
\hline Within Mean & 0.0196 & 0.0196 & 0.0545 & 0.0545 & 0.0348 & 0.0348 \\
\hline Within SD & 0.151 & 0.151 & 0.132 & 0.132 & 0.134 & 0.134 \\
\hline
\end{tabular}


Figure 1: Scope of the paper

This figure depicts the regulatory structure for US Commercial Banks and thrifts in our sample period. The regulatory institutions are the Federal Reserve Banks (Fed), the Federal Depository Insurance Corporation (FDIC), the Office of Comptroller and Currency (OCC), the Office of Thrift Supervision (OTS) and the state banking regulators.

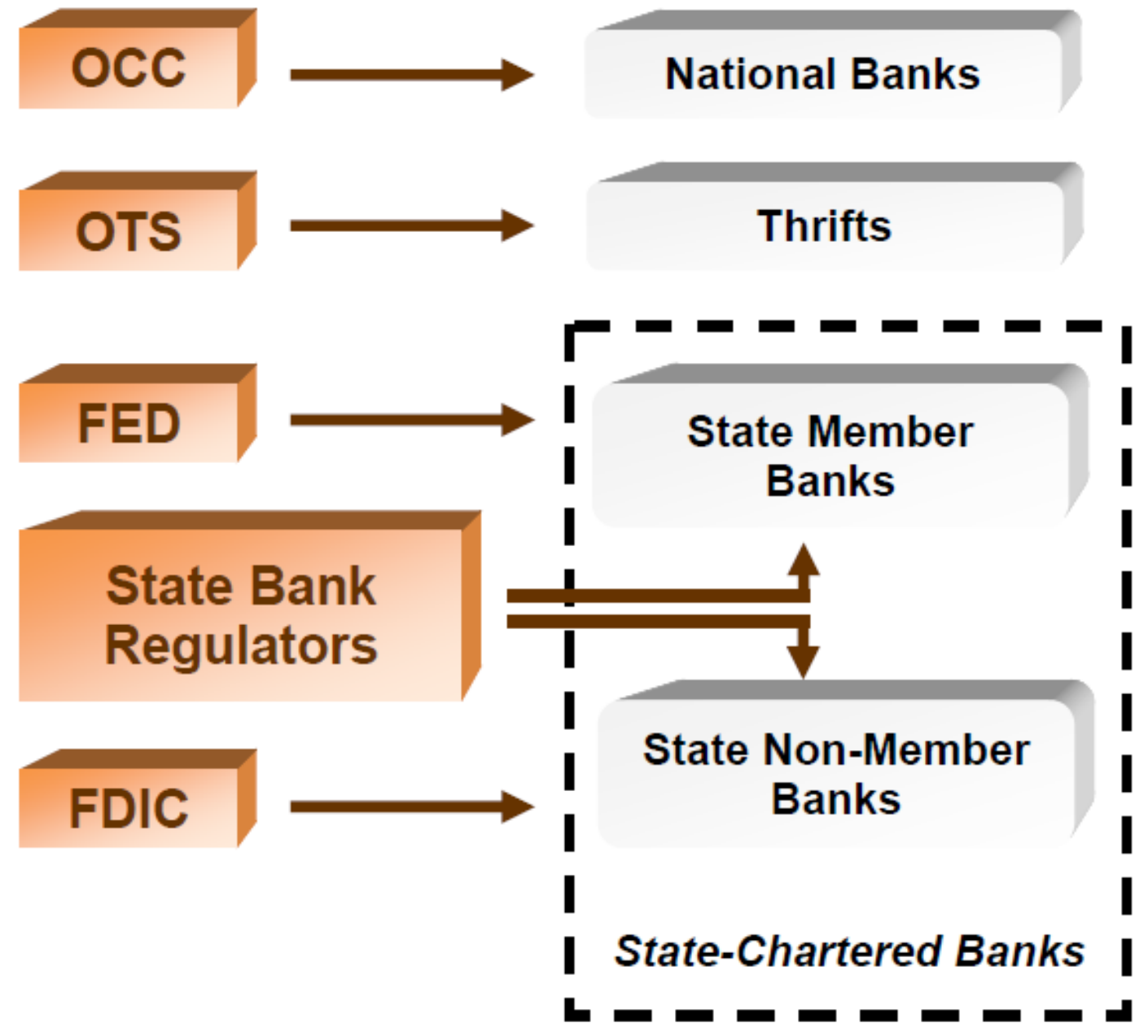




\section{Figure 2: Total number of individuals in our sample and the number split by regulator}

In the left panel, the thick black line shows the active individuals in a given year in the "regulator" sample, i.e., sample of individuals who have worked at any point in time during their careers in the regulatory agencies. The thin grey line shows the active individuals in a given year in the "never-regulator" sample, i.e., sample of individuals who are never employed in the regulatory sector. In the right panel, we plot the number of career active individuals that have worked for a given regulator at a point in time in their career.

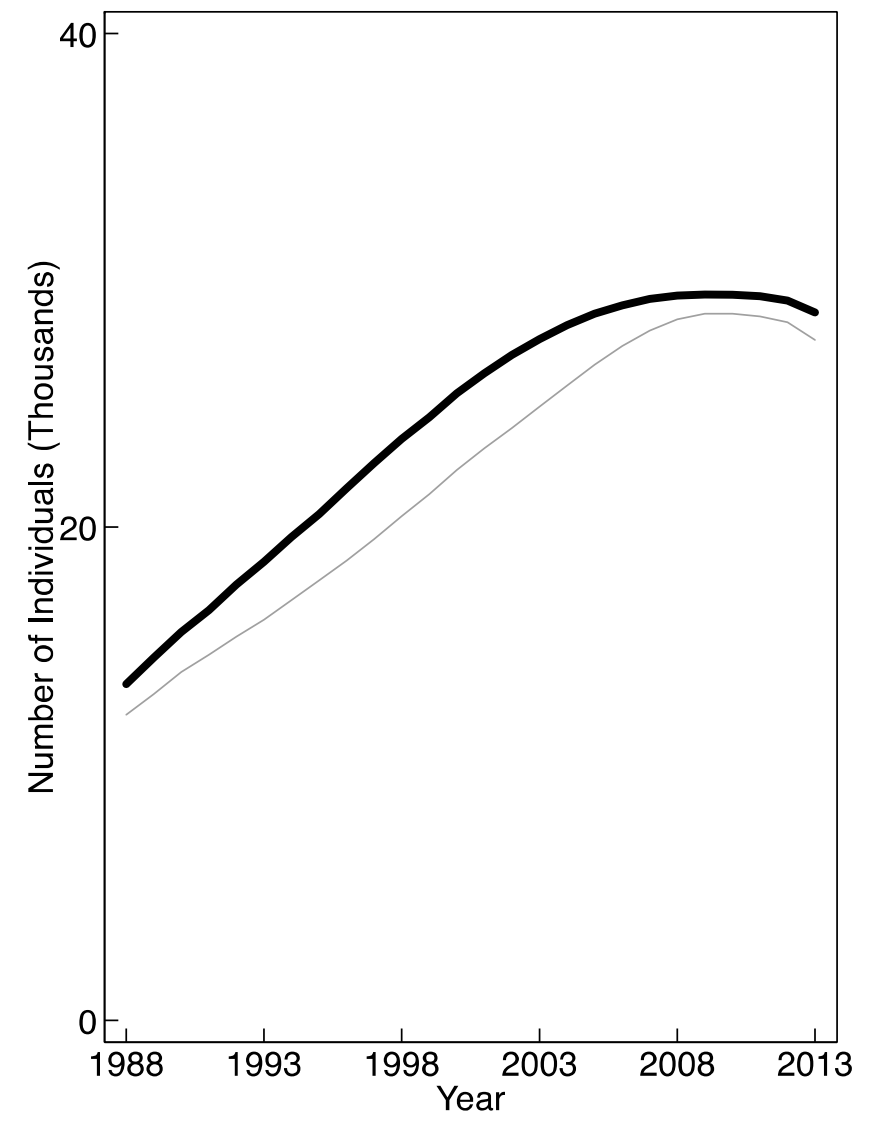

- Regulator Sample - Never-regulator sample

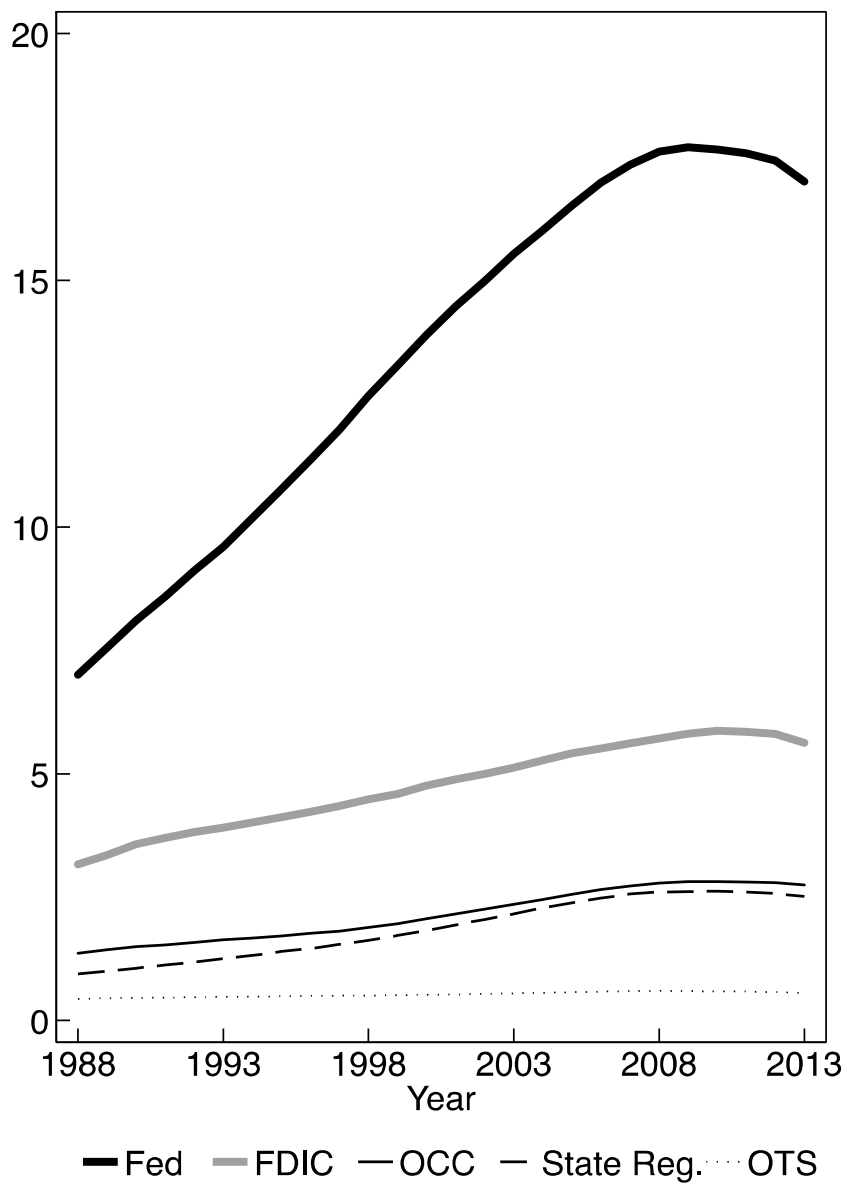




\section{Figure 3: Net Worker Flows into Regulatory Sector}

This figure plots net worker flows (measured on the left-scale) against macroeconomic conditions as measured by real GDP annual growth rates (dashed line) and NBER recessions (shaded vertical areas). Net private-to-regulator worker flows (thick solid line) are defined as the share in each year of all workers in our sample that transition from the private sector to the regulatory sector, less the share of transitions out of the regulatory and into the private sector. We also show total net-regulator flows (thin solid line), which include transitions in and out of the regulatory sector to the private sector, as well as to student status and to unemployment.

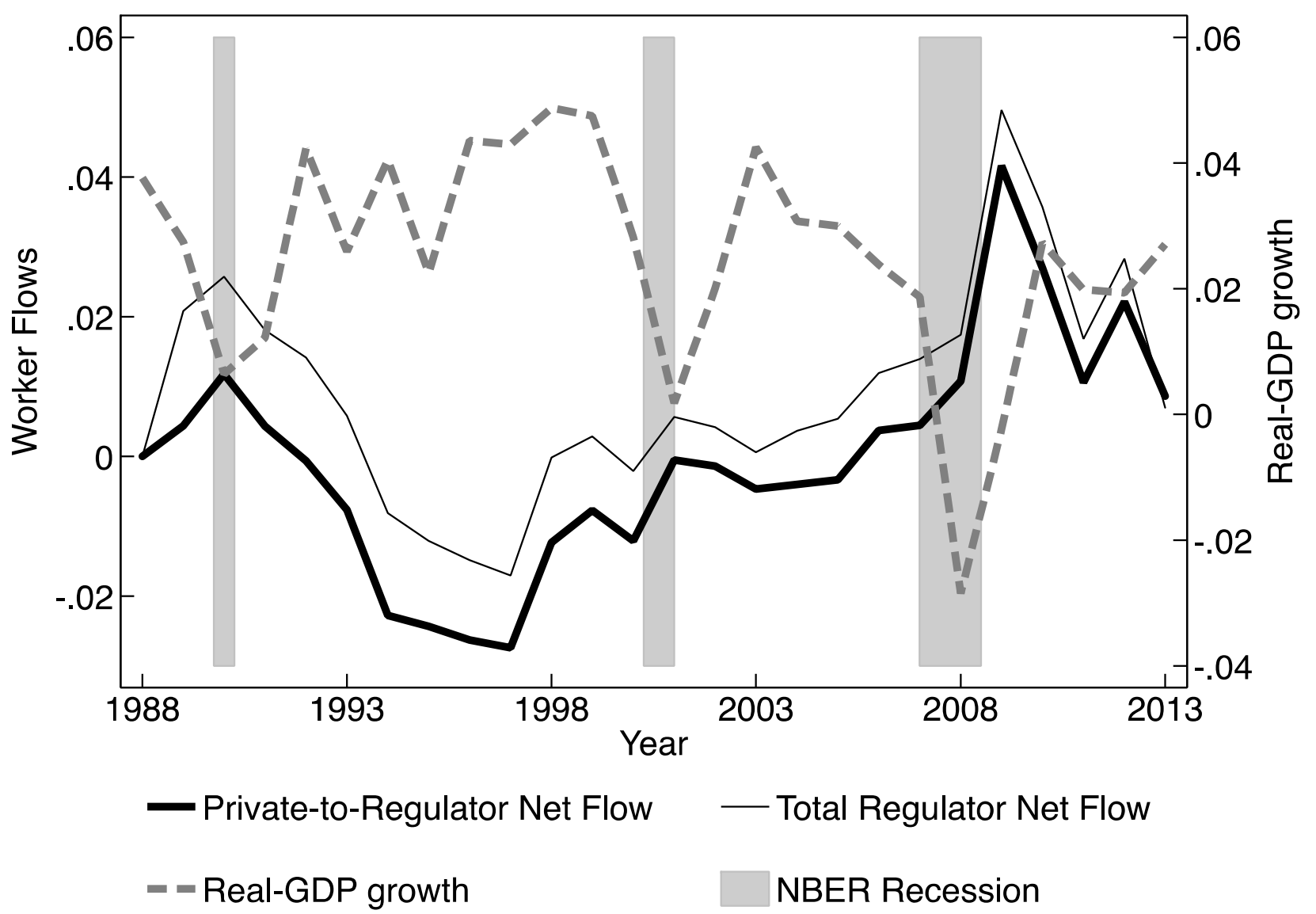




\section{Figure 4: Gross Worker Flows into and out of Regulatory Sector}

This figure shows gross worker flows against macroeconomic conditions as measured by NBER recessions (shaded vertical areas). Gross private-to-regulator worker flows are defined as the share in each year of all workers in our sample that transition from the private sector to the regulatory sector. Gross regulator-toprivate worker flows are defined as the share in each year of all workers in our sample that transition from the regulatory sector into the private sector.

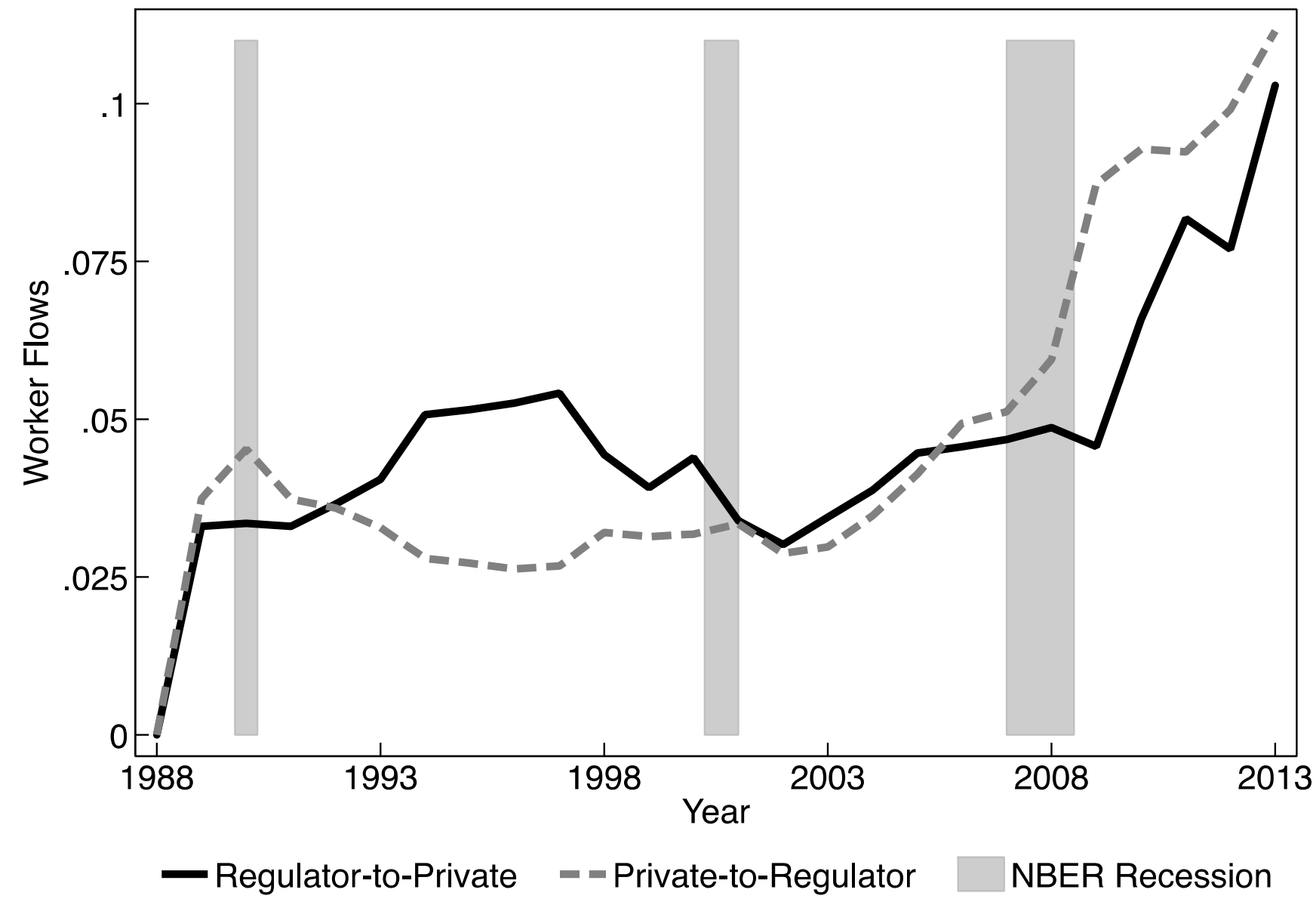

